\title{
Economic Growth and Threatened and Endangered Species Listings: A VAR Analysis ${ }^{\S}$
}

\author{
Catherine M. Chambers ${ }^{1}$, Paul E. Chambers ${ }^{1}$ and John C. Whitehead ${ }^{*} 2$ \\ ${ }^{I}$ Department of Economics and Finance, University of Central Missouri, Warrensburg, MO 64093-5074, USA \\ ${ }^{2}$ Department of Economics, Appalachian State University, Boone, North Carolina 28608-2051, USA
}

\begin{abstract}
We conduct several analyses to examine the link between threatened and endangered species listings and macroeconomic activity. Preliminary tests using ordinary least squares are run on both time series data on the national level and cross sectional data at the state level. The analysis is then extended using vector autoregressive (VAR) techniques. VAR results, impulse response functions and variance decompositions are reported to shed more light on the causal relationships between threatened and endangered species, GDP and population. Our results indicate that there is little or no empirical evidence that GDP growth rates lead to changes in the number of threatened and endangered species listings.
\end{abstract}

Keywords: Economic growth, endangered and threatened species, vector autoregression.

\section{INTRODUCTION}

Environmental economics is a field dominated by microeconomics. Yet macroeconomists have considered both the positive and negative effects of environmental protection on economic growth. Macroeconomists have documented important costs of environmental pollution such as the negative health impacts and the resulting losses in labor productivity. Environmental regulation leads to improved labor productivity and increases in economic growth [1]. On the other hand, environmental regulation diverts business firms' resources away from production, raising the cost of production and leading to lower economic growth [2].

Another macro environmental economic issue is the relationship between Gross Domestic Product (GDP) and environmental quality. In general terms, the Environmental Kuznets Curve (EKC) may be described as an empirical relationship that shows an inverted U-shaped curve relating economic growth to environmental degradation. ${ }^{1}$ In the initial stages of economic development, unregulated economic activity damages the environment. As income grows, the public demand for environmental quality rises and more public policy is focused on environmental protection. For example, Earth Day and the establishment of the Environmental Protection Agency in 1970 were partially the result of a rise in per capita income in the United States.

\footnotetext{
*Address correspondence to this author at the Department of Economics, Appalachian State University, Boone, North Carolina 28608-2051, USA; Tel: (828) 262-6121; E-mail: whiteheadjc@appstate.edu

${ }^{\S}$ A previous version of this paper was presented at the Southern Economic Association annual meetings, New Orleans, LA, 2007.
}

\footnotetext{
${ }^{1}$ Analysis of the environmental Kuznets curve is not limited to empirical analysis. For the theoretical underpinnings, see López [3], Selden and Song [4], Brock and Taylor [5] and Dinda [6].
}

The Environmental Kuznets Curve (EKC) hypothesizes the existence of an inverted U-shaped relationship between national income and pollution. There exists an extensive literature regarding the environmental Kuznets curve (EKC) including the seminal works: Selden and Song [4] Grossman and Krueger [7] and Holtz-Eakin and Selden [8]. Grossman and Krueger [7] find the level of emissions is an increasing function of GDP to a point and then begin to decrease as GDP increases. Selden and Song [4] also found an inverted$U$ relationship between per-capita emissions and per-capita GDP. López [3] provided a theoretical model that supports the inverted-U relationship between per-capita emissions and per-capita GDP.

As Maddison [9] noted, the interest in the EKC is far from declining. The growth in this line of research is demonstrated by the variety of the forms of environmental degradation. Although the initial focus of the EKC works involved emissions such as sulfur dioxide and nitrogen oxide, the scope of research has expanded to other areas of environmental degradation such as water pollutants (see Paudel, Zapata and Susanto [10]), deforestation (Koop and Tole [11]) and biodiversity in terms of threatened species (Naidoo and Adamowicz [12]).

Using international cross sectional data, Naidoo and Adamowicz [12] find that a small number of species showed the characteristics of an environmental Kuznets curve. Many taxonomic groups show an increase in the number of the threatened species over the range of income. Also using international data, Dietz and Adger [13] do not find an EKC for biodiversity. In contrast to Naidoo and Adamowicz [12] and Dietz and Adger [13], our focus is on threatened and endangered species listings in the U.S. Previous research using these data is limited.

In addition to the EKC literature, others have investigated the links between GDP and the endangerment of species. For example, Czech, Krausman and Devers [14] used a bivariate regression of federally listed species (i.e., Endangered 
Species Act) on GDP from 1972-2003 as empirical evidence of the correlation between macroeconomic growth and fish conservation. Reed and Czech [15] provided similar evidence for fish species.

One of the difficulties in determining the effect of economic growth on environmental issues such as biodiversity is the problem of measurement. There are several measures of biodiversity commonly used by environmental scientists, including but not limited to the Simpson index, the Shannon index and various distance functions. Each of these measures has its own strengths and weaknesses, and none is universally accepted as a perfect measure. In fact, even defining biodiversity is a controversial endeavor. However, one cannot argue with the fact that increasing the number of native species in peril does not bode well for biodiversity. Rather than solving the problem, however, this merely shifts the focus of debate to the question of measuring the number of species in peril and tracking that number over time. For reasons discussed below, the number of officially classified threatened and endangered species in the U.S. is an imperfect estimate of the number of species in peril. However, there are no other readily available sources of data on how the level of threat to species changes listing decisions reflect the preference for charismatic macrofauna over science (Metrick and Weitzman [17]) and the importance of interest group politics (Ando [18]). These additional factors are not considered as independent variables in current empirical research. Econometrically, omitted variable bias can lead to statistically significant, unexpected signs on the coefficients.

In this paper, we conduct several analyses to examine the link between threatened and endangered species and macroeconomic activity. Preliminary tests using ordinary least squares are run on both time series data at the national level and cross sectional data at the state level. The analysis is then extended using vector autoregressive techniques. VAR results, impulse response functions and variance decompositions are reported to shed more light on the causal relationships between threatened and endangered species, GDP and population.

\section{DATA AND PRELIMINARY MODELS}

The time-series analysis is conducted with thirty years of annual data from 1973-2002 (Table 1). The cumulative number of threatened and endangered species (TES) is obtained from the U.S. Fish and Wildlife Service. The annual number of TES is constructed from the cumulative

Table 1. Time Series Data

\begin{tabular}{|c|c|c|c|c|}
\hline & Mean & Std. Dev. & Minimum & Maximum \\
\hline Annual Threatened and Endangered Species Listings & 39.97 & 30.66 & 0 & 126 \\
\hline Gross Domestic Product $(\$ 100,000 \mathrm{~s})$ & 6737.48 & 1818.09 & 4311.20 & 10048.80 \\
\hline Per Capita Gross Domestic Product $(\$ 1000$ s) & 27.02 & 4.88 & 19.96 & 34.89 \\
\hline Cases $=30$ & & & & \\
\hline
\end{tabular}

over time. While sites such as NatureServe report the number of species facing various levels of peril, these data are not reported in time series form. According to a data analyst at NatureServe, the data are not designed to be used to track the recovery or decline of a species over time for several reasons: changes in rank may occur due to increases in knowledge about the species rather than a change in the degree to which it is threatened; changes in rank may occur due to taxonomic changes, for example when two populations previously classified as separate species are redefined as one species; some species may have low but stable populations by nature, even though they are under little or no threat. Therefore, like previous researchers, we will use the number of species listed under the Endangered Species Act (ESA), with the caution that this may be an imperfect proxy.

The number of listed species under the ESA is determined by a number of factors including government budget constraints. Limited government resources devoted to listing decisions force the cumulative number of species listed to increase over time (Brown and Shogren [16]). Also, species listing decisions are not perfect measures of endangered status (Brown and Shogren [16]). For example, data. The average number of TES listings annually is about 40. Annual gross domestic product data is obtained from the U.S. Bureau of Economic Analysis. Annual population data is obtained from the U.S. Census Bureau.

We first replicated the results summarized in Czech, Krausman and Devers [14] and Reed and Czech [15]. Using ordinary least squares regression analysis, we find an $\mathrm{R}^{2}=.98$ when GDP is regressed on cumulative TES listings. In Table 2, we present four time-series regression models. We consider both the stock dependent variable of cumulative TES listings and the flow dependent variable of annual TES listings. Two models are estimated with each dependent variable. The first includes only annual GDP as the independent variable. The second decomposes annual GDP into per capita GDP and the population growth. ${ }^{2}$ Because the error terms are often correlated over time with time-series data, we use a model that accounts for the serial correlation. Ordinary least squares results are qualitatively similar.

\footnotetext{
${ }^{2}$ We also considered the flow variable population growth with little difference in results.
} 
Table 2. Time Series Data Models*

\begin{tabular}{|c|c|c|c|c|c|c|c|c|}
\hline & \multicolumn{8}{|c|}{ Threatened and Endangered Species Listings } \\
\hline & \multicolumn{2}{|c|}{ Cumulative } & \multicolumn{2}{|c|}{ Cumulative } & \multicolumn{2}{|c|}{ Annual } & \multicolumn{2}{|c|}{ Annual } \\
\hline & Coeff. & t-Ratio & Coeff. & t-Ratio & Coeff. & t-Ratio & Coeff. & t-Ratio \\
\hline Constant & -804.02 & -6.01 & & & -0.021 & 0.00 & 175.90 & 0.82 \\
\hline Gross Domestic Product $(\$ 100,000 \mathrm{~s})$ & 0.19 & 11.33 & & & 0.006 & 1.38 & & \\
\hline Per Capital Gross Domestic Product $(\$ 1000 \mathrm{~s})$ & & & 34.21 & 3.74 & & & 9.91 & 1.27 \\
\hline Change in Annual Population $(1,000,000 \mathrm{~s})$ & & & 8.77 & 4.28 & & & -1.65 & -0.97 \\
\hline$\rho$ & 0.94 & 14.45 & 0.95 & 15.95 & 0.37 & 2.13 & 0.30 & 1.70 \\
\hline Durbin-Watson & \multicolumn{2}{|c|}{1.50} & \multicolumn{2}{|c|}{1.41} & \multicolumn{2}{|c|}{2.29} & \multicolumn{2}{|c|}{2.26} \\
\hline
\end{tabular}

*AR(1) Model: $e(t)=\rho^{*} e(t-1)+u(t)$.

We find that GDP is positively correlated with cumulative TES listings. GDP per capita and population are also positively correlated with cumulative TES listings. But, as stated previously, cumulative TES listings are a stock variable and will increase over time by definition. In our annual TES listing models, we find that neither GDP nor GDP per capita and population have any statistically significant impact on TES listings.

As an alternative model of the impact of economic growth on TES listings, we consider cross-sectional data for the 48 mainland states. The dependent variable is the number of threatened and endangered species listed in each state according to the USFWS. The independent variables include the decomposed measures of regional economic growth in each state for 2004: State per capita personal income is obtained from the U.S. Bureau of Economic Analysis and state population data are obtained from U.S. Bureau of the Census. Control variables are the land area and inland water area in each state, both of which are measured in thousands of square miles. In addition we include Census Region dummy variables to control for regional variation in TES listings (Table 3).

Correlations among these variables indicates that per capita income has little correlation with species listings $(\mathrm{r}=$ $0.02)$ but population is highly correlated $(\mathrm{r}=0.75)$. To determine the impact of per capita income and population on species listings while holding other factors constant, we estimate a multivariate regression model. The ordinary least squares regression analysis reveals that increases in human population increase the number of listed species (Table 4). The most striking result is that increases in per capita income lead to decreases in the number of listed species. The independent variables explain almost all of the variation in the dependent variable, which is quite high for state level cross-sectional data.

One criticism of the cross-section results is that they do not measure regional (measured at the state-level) economic growth because they are a snapshot in time. As one potential way of addressing this, we consider the time period of 19722004 and consider regional economic growth and the change of TES listings over that time period. Because TES listings began in 1973, the state-level listings in 2005 also measure the change over this time period.
We compute the state level change in per capita personal income and population from 1972 - 2004 and include these variables in another set of cross-section regression models. We find results similar to the cross-section results. Population growth from 1972 - 2004 is positively correlated with TES listings. Per capita personal income growth from $1972-2004$ is negatively correlated with TES listings, although this effect is not strongly statistically significant $(\mathrm{p}=0.10)$.

\section{VAR MODELS}

Simple OLS regressions can provide suggestive results regarding the relationships between variables, but one can draw only tentative conclusions regarding causality from such results. To further examine the relationship between the number of threatened and endangered species, population, and GDP, we employ several techniques based on VAR models. Let the dependent variable of equation of $i$ be written as $y_{i}=\left[y_{\left.i 1, \ldots ., y_{i T}\right]}\right.$, where $T$ is the sample size in terms of years. Let $\mathrm{Y}^{*}$ be a (T x k) matrix of regressors of lagged value of the $y_{i}$ 's where $k=p N$ with $p$ being the number of lags and $\mathrm{N}$ being the number of variables. In general, the model is given by

$$
\left[\begin{array}{c}
y_{1} \\
y_{2} \\
\vdots \\
y_{N}
\end{array}\right]=\left[\begin{array}{ccccc}
Y^{*} & 0 & 0 & \cdots & 0 \\
0 & Y^{*} & 0 & \cdots & 0 \\
\vdots & \vdots & \vdots & \ddots & \vdots \\
0 & 0 & 0 & \cdots & Y^{*}
\end{array}\right]\left[\begin{array}{c}
\beta_{1} \\
\beta_{2} \\
\vdots \\
\beta_{n}
\end{array}\right]+\left[\begin{array}{c}
\varepsilon_{1} \\
\varepsilon_{2} \\
\vdots \\
\varepsilon_{N}
\end{array}\right] .
$$

In our specification, we consider a three equation, second order VAR using real GDP, population and the cumulative number of endangered species. ${ }^{3}$

The results of this VAR are given in Table 5. In the GDP equation, the first and second lags of GDP and the second lag of population are significant $(\mathrm{p}=0.01,0.05$ and 0.05 respectively). F-tests indicate that lagged values of GDP are highly significant and lagged values of population are significant at the $5 \%$ level. Lags of species are insignificant individually and jointly, as indicated by the F-test. The only

\footnotetext{
${ }^{3}$ We also tested a number of alternative specifications using real GDP, population and annual listings; per capita GDP, population and annual listings; and per capita GDP, population and cumulative number of TES. Our results were similar across all models.
} 
Table 3. Cross-Section Data

\begin{tabular}{|c|c|c|c|c|}
\hline Threatened and Endangered Species Listed in State & 42.54 & 46.50 & 9 & 308 \\
\hline Population $(1,000,000 \mathrm{~s}, 2004)$ & 6.07 & 6.58 & 0.51 & 35.84 \\
\hline Per Capita Personal Income Growth (1000s, 1972-2004) & 11.81 & 2.69 & 8.08 & 19.58 \\
\hline Land Area (1000s of square miles) & 61.65 & 46.81 & 1.04 & 261.80 \\
\hline Inland Water Area (1000s of square miles) & 12.39 & 24.50 & 0.36 & 121.59 \\
\hline Northeast Region & 0.13 & 0.33 & 0 & 1 \\
\hline East South Central Region & 0.08 & 0.28 & 0 & 1 \\
\hline West South Central Region & 0.08 & 0.28 & 0 & 1 \\
\hline Mountain Region & 0.17 & 0.38 & 0 & 1 \\
\hline Pacific Region & 0.06 & 0.24 & 0 & 1 \\
\hline South Atlantic Region & 0.17 & 0.38 & 0 & 1 \\
\hline Cases $=48$ & & & & \\
\hline
\end{tabular}

significant variables in the population equation are lagged values of population itself. The first lag of population is significant at the $1 \%$ level and F-tests indicate that the first and second lags are jointly significant. The two lags of real GDP are jointly significant at the $10 \%$ level. Our main interest, however, is with the species equation. Note that none of the lags of real GDP or population are significant individually or jointly. Thus, it does not appear that changes in population or GDP have significant impact on the cumulative number of threatened and endangered species.

Like OLS results, the results of this VAR provide some insight into the relationships between the three variables included. To further explore the causal relationships involved, we used this VAR to conduct two additional forms of analysis. First, we estimated impulse response functions, which measure the responses of each variable in the system to a shock to one of those variables. We measured these responses for ten periods. For example, if there is a shock to real GDP at time (t), the impulse response functions estimate the response of GDP, population and the cumulative number of species at each point in time from $(t)$ to $(t+9)$. The impulse responses, however, are point estimates, and can therefore be misleading. If there is a positive response to a shock to population, is that response significant or merely a statistical coincidence? In order to answer this question, we used Monte Carlo integration to construct confidence bands around our impulse response functions. The impulse responses with confidence bands are shown in Fig. (1). A response is significant if the confidence band does not include zero.
When a shock is imposed on real GDP, there is a positive and significant response of real GDP contemporaneously and for the next three periods. The response then becomes insignificant, but is again significant for periods 7, 8 and 9 . Although population does not immediately respond to the change in real GDP, after 2 periods the response is positive and significant and remains so in all subsequent periods. The more interesting result for our analysis is the fact that the response of the cumulative number of species is never significant (although it is generally positive). A shock to population creates a significant positive response in real GDP after four periods and significant responses in population at each step. Again, the response of species is insignificant throughout. The only significant response by species is to shocks to species itself. Interestingly, both real GDP and population (of humans) also respond positively to shocks to species, GDP after two periods and population after five.

The final analysis we performed was a variance decomposition. The VAR is used to compute forecasts for each of the variables in the system and the standard error of the forecasts is estimated. The variance of this forecast error is then broken down into the proportion that can be attributed to innovations in each variable (Table 6). Whereas the total variance of forecast standard error does not depend on the ordering of variables in the equation, the decomposition of that variance does. For that reason, we ran this test using several possible orderings. Results were not significantly different. Variables listed first are expected to have the greatest predictive power, whereas the last variable is expected to have no predictive value. The variance 
Table 4. Cross-Section Data Models*

\begin{tabular}{|c|c|c|c|c|}
\hline & Coeff. & t-Ratio & Coeff. & t-Ratio \\
\hline Per Capita Personal Income (1000s, 2004) & -1.18 & -2.22 & & \\
\hline Population $(1,000,000 \mathrm{~s}, 2004)$ & 7.27 & 7.36 & & \\
\hline Population Growth (1000s, 1972-2004) & & & 0.72 & 7.19 \\
\hline Land Area (1000s of square miles) & -0.24 & -2.63 & -0.22 & -2.30 \\
\hline Inland Water Area (1000s of square miles) & 0.03 & 0.34 & 0.04 & 0.53 \\
\hline West North Central Region & 1.74 & 0.22 & 3.86 & 0.47 \\
\hline East South Central Region & 35.09 & 2.31 & 39.64 & 2.61 \\
\hline West South Central Region & -7.76 & -1.18 & -4.96 & -0.68 \\
\hline Mountain Region & 27.04 & 2.53 & 22.97 & 2.24 \\
\hline Pacific Region & 40.31 & 2.27 & 38.41 & 2.16 \\
\hline $\mathrm{R}^{2}$ & \multicolumn{2}{|c|}{0.88} & \multicolumn{2}{|c|}{0.88} \\
\hline $\mathrm{F}$ & \multicolumn{2}{|c|}{22.53} & \multicolumn{2}{|c|}{21.93} \\
\hline
\end{tabular}

decompositions reported here are based on the ordering: real GDP, population, species. This ordering will result in the strongest possible impact of innovations in real GDP on species (and conversely, the weakest impact of species on real GDP).

For real GDP, the forecast error is explained only by innovations in GDP for the first step. But note that the percentage of variance explained by innovations in population and species increases at the longer steps. After ten steps, over $32 \%$ of the variance is explained by innovations in species, $14.5 \%$ by innovations in population and $52 \%$ by innovations in real GDP. The variance of forecast error for population is largely explained by innovations in real GDP after three steps. After seven steps, real GDP becomes more important than population itself. For species, however, over $90 \%$ of the forecast error variance is explained by innovations in species itself. Innovations in real GDP and population do not have a strong impact on species.

\section{ALTERNATIVE EXPLANATIONS}

Given that our results suggest that real GDP and population do not explain the variations in the number of threatened and endangered species listings, are there alternative explanations for the number of threatened and endangered species listings? Loss of habitat and habitat fragmentation are well known sources of species extinction
Table 5. Vector Autoregression Results

\begin{tabular}{|c|c|c|c|}
\hline & Real GDP & Population & TES \\
\hline \hline RGDP $_{\mathrm{t}-1}$ & $\begin{array}{c}1.15 \\
\left(6.03^{* * *}\right)\end{array}$ & $\begin{array}{c}.003 \\
\left(1.70^{*}\right)\end{array}$ & $\begin{array}{c}.003 \\
(.06)\end{array}$ \\
\hline RDGP $_{\mathrm{t}-2}$ & $\begin{array}{c}-.47 \\
\left(-2.29^{* *}\right)\end{array}$ & $\begin{array}{c}-.00006 \\
(-.03)\end{array}$ & $\begin{array}{c}-.03 \\
(-.53)\end{array}$ \\
\hline Population $_{\mathrm{t}-1}$ & -23.11 & .56 & -3.35 \\
& $(-1.20)$ & $\left(2.66^{* * *}\right)$ & $(-.64)$ \\
\hline Population $_{\mathrm{t}-2}$ & 39.80 & .18 & 6.59 \\
& $\left(2.31^{* *}\right)$ & $(.96)$ & $(1.40)$ \\
\hline Cumulative \# Species $\mathrm{t}-1$ & .35 & .008 & 1.22 \\
& $(.42)$ & $(.90)$ & $(5.34 * * *)$ \\
\hline Cumulative \# Species $\mathrm{t}_{\mathrm{t}-2}$ & .31 & .009 & -.25 \\
& $(.36)$ & $(.92)$ & $(-1.06)$ \\
\hline F-tests & & & \\
RGDP & $21.70^{* * *}$ & $2.73^{*}$ & .23 \\
Population & $3.71^{* *}$ & $22.04^{* * *}$ & 1.53 \\
Species & 1.68 & .43 & $56.45^{* * *}$ \\
\hline
\end{tabular}

$\mathrm{t}$-Statistics in parentheses.

*** Significant at the $1 \%$ level.

** Significant at the $5 \%$ level.

* Significant at the $10 \%$ level.

(for example, see Pearce and Moran [19]; Lawton and May [20]; Jenkins [21]). Unfortunately, there is not a simple, 
Table 6. Variance Decompositions

\begin{tabular}{|c|c|c|c|c|}
\hline \multicolumn{5}{|c|}{ Decomposition of Variance for Real GDP } \\
\hline Step & Standard Error & RGDP & Population & Species \\
\hline 1 & 91.21 & $100 \%$ & $0.00 \%$ & $0.00 \%$ \\
\hline 2 & 140.56 & $96.94 \%$ & $2.70 \%$ & $0.36 \%$ \\
\hline 3 & 163.50 & $93.88 \%$ & $2.00 \%$ & $4.12 \%$ \\
\hline 4 & 176.91 & $86.26 \%$ & $3.07 \%$ & $10.67 \%$ \\
\hline 5 & 189.64 & $76.46 \%$ & $6.27 \%$ & $17.26 \%$ \\
\hline 6 & 201.88 & $68.16 \%$ & $9.62 \%$ & $22.22 \%$ \\
\hline 7 & 212.95 & $62.26 \%$ & $11.99 \%$ & $25.75 \%$ \\
\hline 8 & 223.39 & $58.24 \%$ & $13.34 \%$ & $28.42 \%$ \\
\hline 9 & 233.90 & $55.32 \%$ & $14.06 \%$ & $30.63 \%$ \\
\hline 10 & 244.71 & $52.85 \%$ & $14.50 \%$ & $32.65 \%$ \\
\hline \multicolumn{5}{|c|}{ Decomposition for Population } \\
\hline 1 & 1.00 & $1.74 \%$ & $98.26 \%$ & $0.00 \%$ \\
\hline 2 & 1.22 & $9.52 \%$ & $87.75 \%$ & $2.73 \%$ \\
\hline 3 & 1.42 & $23.38 \%$ & $73.92 \%$ & $2.70 \%$ \\
\hline 4 & 1.61 & $36.12 \%$ & $61.76 \%$ & $2.12 \%$ \\
\hline 5 & 1.77 & $43.69 \%$ & $53.60 \%$ & $2.71 \%$ \\
\hline 6 & 1.92 & $46.40 \%$ & $48.51 \%$ & $5.09 \%$ \\
\hline 7 & 2.07 & $45.98 \%$ & $45.22 \%$ & $8.79 \%$ \\
\hline 8 & 2.21 & $44.16 \%$ & $42.85 \%$ & $12.99 \%$ \\
\hline 9 & 2.36 & $42.02 \%$ & $40.88 \%$ & $17.10 \%$ \\
\hline 10 & 2.51 & $40.06 \%$ & $39.08 \%$ & $20.86 \%$ \\
\hline \multicolumn{5}{|c|}{ Decomposition of Variance for Species } \\
\hline 1 & 24.98 & $5.08 \%$ & $.01 \%$ & $94.91 \%$ \\
\hline 2 & 39.46 & $4.90 \%$ & $.86 \%$ & $94.24 \%$ \\
\hline 3 & 50.11 & $3.68 \%$ & $.54 \%$ & $95.79 \%$ \\
\hline 4 & 57.95 & $2.76 \%$ & $.90 \%$ & $96.34 \%$ \\
\hline 5 & 63.81 & $2.29 \%$ & $1.90 \%$ & $85.80 \%$ \\
\hline 6 & 68.11 & $2.01 \%$ & $3.02 \%$ & $94.97 \%$ \\
\hline 7 & 71.31 & $1.91 \%$ & $3.95 \%$ & $94.15 \%$ \\
\hline 8 & 73.88 & $2.07 \%$ & $4.67 \%$ & $93.26 \%$ \\
\hline 9 & 76.15 & $2.51 \%$ & $5.24 \%$ & $92.25 \%$ \\
\hline 10 & 78.30 & $3.10 \%$ & $5.77 \%$ & $91.13 \%$ \\
\hline
\end{tabular}

generally accepted definition for habitat, especially given the magnitude of the land mass considered in our study. ${ }^{4}$ Compounding the conceptual problems associated with

\footnotetext{
${ }^{4}$ To illustrate this difficulty, Rosenzweig [22] notes that earlier studies found over twenty types of habitat varieties for woodland mites. In more general terms, Vanreuse and Hans Van Dyck [23] state that "[t]he unambiguous recognition of a species' habitat is a matter of debate. "
}

defining habitat are data limitations. If one was to consider forest area as a measure of habitat, a potentially poor proxy given the variety of forest cover, one would find incomplete time series regarding this measure.

Greenwald, Suckling and Taylor [24] suggest an alternative explanation for the variations in the species. They argue that the differences in listings are largely due to changes in the administrative environment. They divide the post-ESA era (from 1974-2003) into four distinct periods based on major changes in the regulatory environment. According to the authors, in the years immediately following the passage of the Endangered Species Act, listings increased steadily. In 1978, Congress amended the act to require that any proposal for listing be withdrawn if it was not finalized within two years. The amendment also prohibited listings from being re-proposed unless new information came to light and required the designation of "critical habitat." When these changes were implemented, the number of listings dropped dramatically. Shortly after taking office in 1981, Ronald Reagan issued an executive order requiring an economic impact analysis prior to listing. As a result of this order, combined with additional bureaucratic reviews, in 1981, for the first time since the ESA was passed, no species were listed.

The second period described by Greenwald, Suckling and Taylor [24] is 1983-1990. In 1982, Congress amended the ESA again to reduce administrative delays in the listing process. Congress also reversed the Reagan administration's economic impact requirement. As a result, the number of listings increased to an average of forty species per year for this period. There was another dramatic increase in the number of listings starting in 1991. This shift was caused primarily by a series of petitions and lawsuits by NGOs designed to force the USFWS to move quickly in listing the backlog of candidate species. During the period 1991-1995 (Period three), $66 \%$ of species were listed following lawsuits. Following this sharp increase in the number of listings, Congress imposed a twelve month moratorium on the listing program from April 1995 - April 1996.

The final period examined is 1996-2004. In 1995, the Interior Department issued a policy prohibiting NGOs from petitioning to list a species that was currently on the candidate list. This limited the use of lawsuits to increase listings. To address the issue of petitions on species not on the candidate list, the USFWS began using a statutory provision that allowed them to delay issuing initial findings if it was "not practicable". The final factor influencing the number of listings per year is funding. Despite the large backlog of candidate species and the additional workload created by amendments to the ESA, the Department of the Interior has not requested sufficient funds to keep up with the workload. In fact, in 1998, it requested that Congress legislatively cap the amount of funds available for the listing process. This cap has been renewed at the request of the Secretary of the Interior every year from 1999-2004.

Although it appears that political factors affect the listing process, changes in the regulatory environment are difficult to specify for a multitude of reasons. Both Democratic and Republican administrations have mixed records regarding 


\section{impulse responses}

RGDP
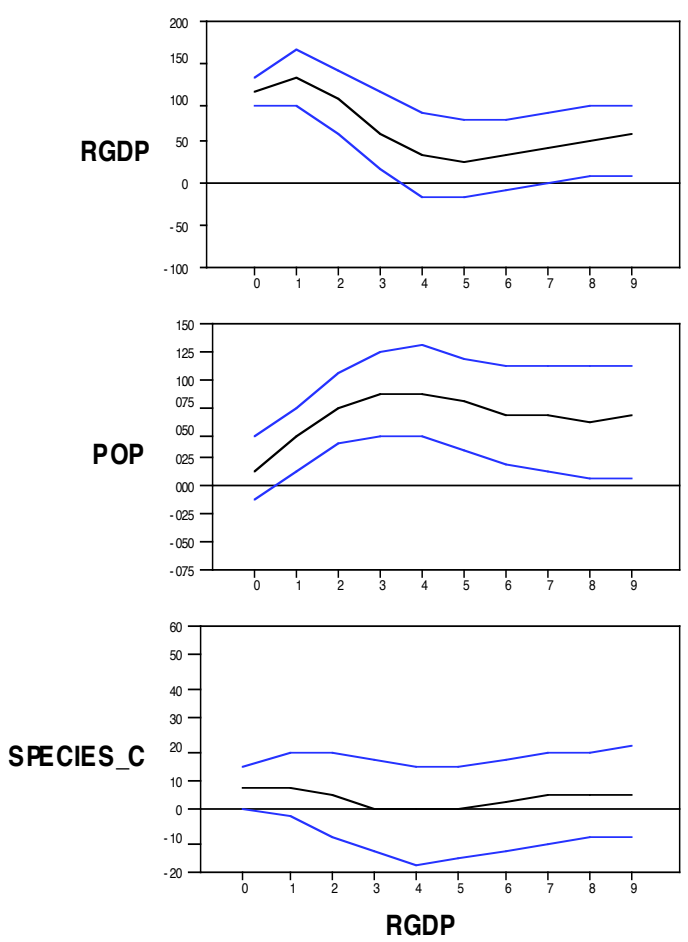

POP
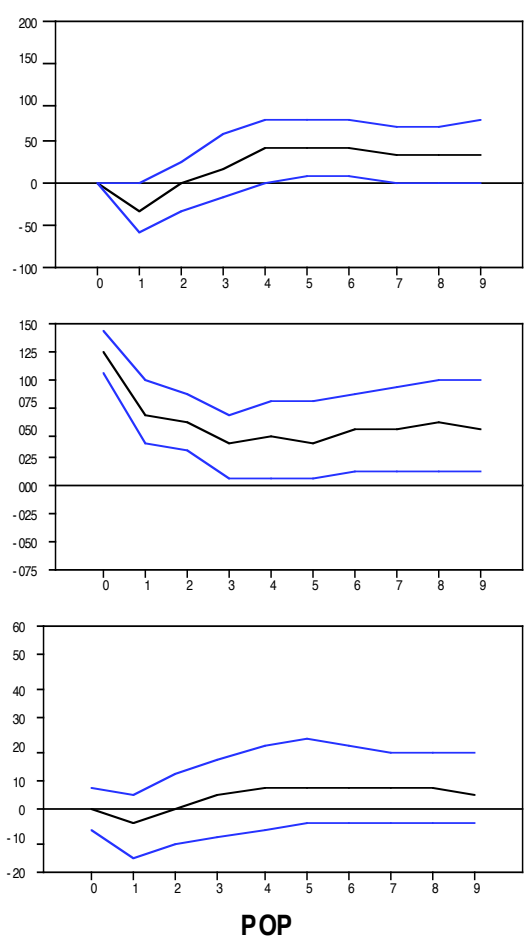

SPECIES_C
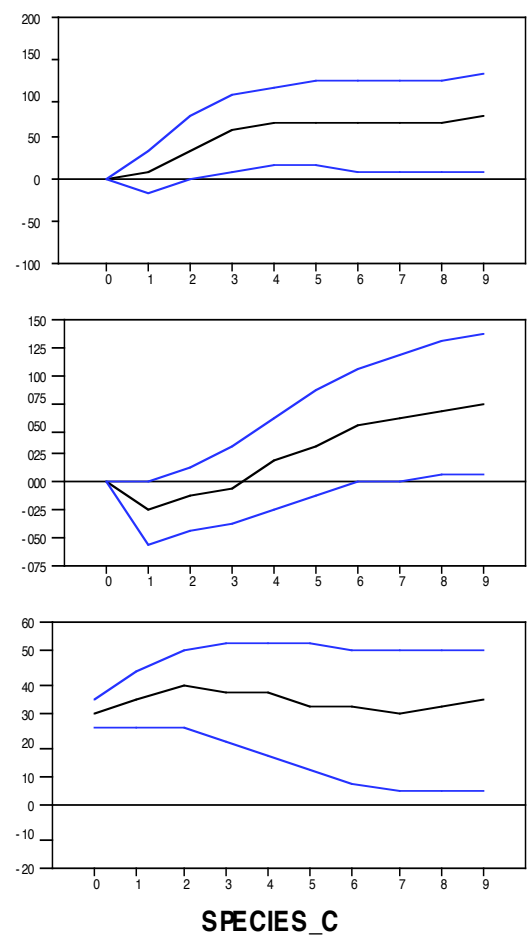

Fig. (1).

listing. Alternatively, political influences may be detected through a structural break. Unfortunately, the limited numbers of years since passage of the ESA combined with the high number of potential regimes implied by Greenwald, Suckling and Taylor [24], limits the use of tests for structural change. However, we did run several stability tests which provide suggestive results. All tests were performed on a simple regression with cumulative species as the dependent variable and real GDP and population as independent variables. The first test is a CUSUM test (Brown, Durbin and Evans [25]), which uses recursive estimation. The null hypothesis is that the recursive residuals should act as a random walk. If they do not, there is evidence of a structural break. Results from this test, shown in Fig. (2), indicate that there is a break in 1994, which represents the boundary between the third and fourth periods identified by Greenwald, Suckling and Taylor [24]. A Hansen [26] test for parameter stability also rejects the null that the coefficients and variance of the regression are jointly constant at the $1 \%$ level. Finally, using a series of Chow tests with hypothesized breaks in 1982, 1991, and 1995 (the break points in the periods described by Greenwald, Suckling and Taylor [24]) we can reject the null hypothesis of no structural shift at the $1 \%$ level for two of these shifts. There does not appear to be a significant structural break in 1995. Results of the Hansen [26] and Chow tests are shown in Table 7. Whereas all of these results indicate at least one structural break, they should be interpreted with caution due to the limited size of the data set, as noted above.

More recent events suggest that political appointees may be influencing the listing process. Stokstad [27] notes that
Julie MacDonald, deputy assistant secretary at the U.S. Department of the Interior, "intimidated U.S Fish and Wildlife Service scientists to alter biological reports about endangered species". Less than a month after the publication of Stokstad's Science article and a week prior to appearing in front of a House oversight committee, MacDonald resigned. ${ }^{5}$

\section{CONCLUSIONS}

We find that in simple OLS models GDP is positively correlated with cumulative threatened and endangered species (TES) listings. GDP per capita and population are also positively correlated with cumulative TES listings. However, in our annual TES listing models, we find that neither GDP nor GDP per capita and population have any statistically significant impact on TES listings. With the more rigorous vector autoregressive analysis (VAR), we find that neither GDP nor population affects TES listings.

Our results indicate that there is little or no evidence that GDP growth rates lead to changes in the number of threatened and endangered species listings. The possible explanations are varied. As Kongsamut et al. [29] found, cleaner service sectors increase as economies grow. Increases in GDP fueled by growth in these sectors may have little or no negative impact on the environment. Also, because environmental protection is a normal good, rising incomes lead to greater demand for programs that will protect species. Including spending on such programs in a

${ }^{5}$ Eilperin [28] reported that various allegations against MacDonald were under investigation by the inspector general of the Department of Interior. 


\section{cusum test}

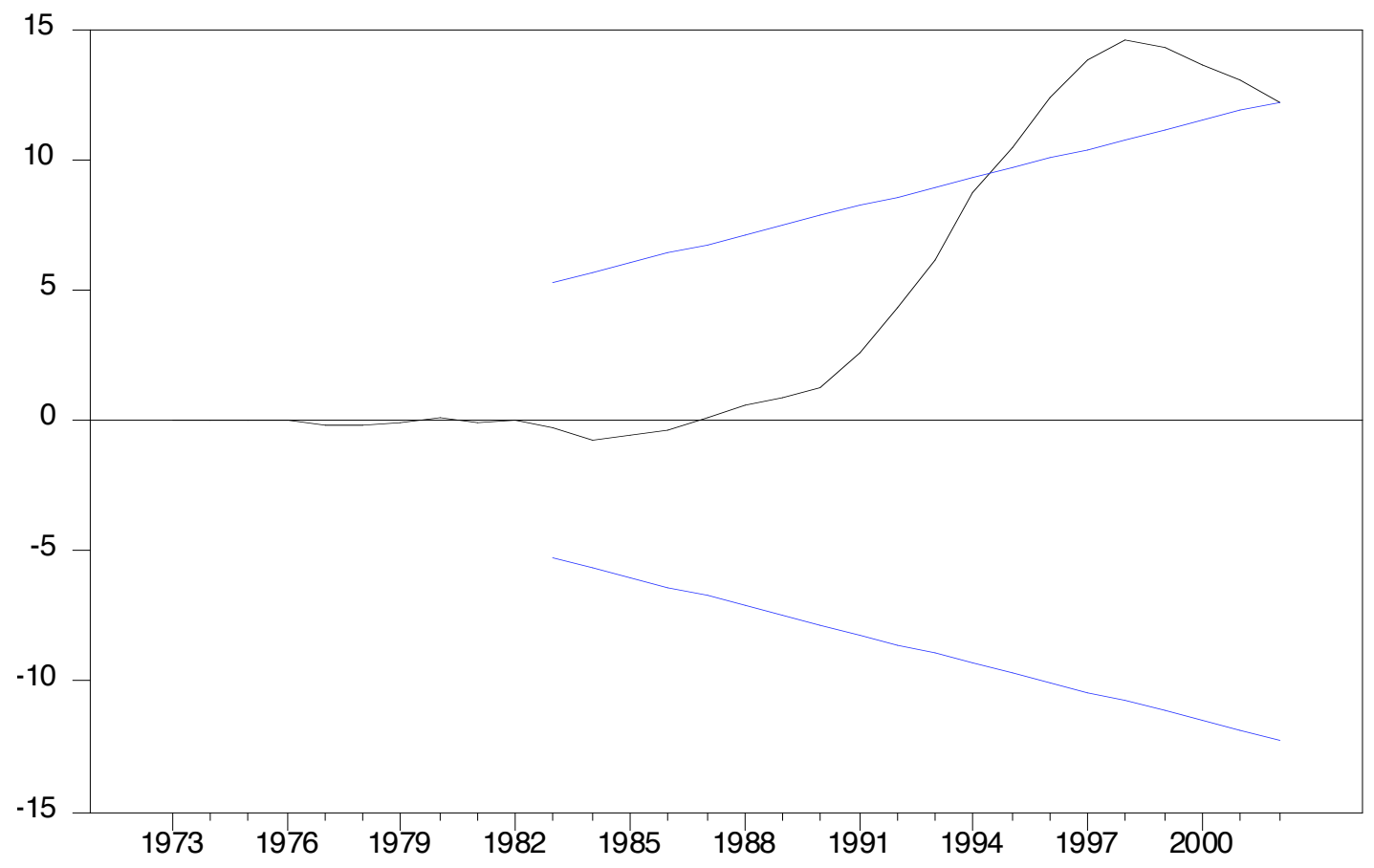

Fig. (2).

vector autoregressive system would elucidate its relationships to GDP and threatened and endangered species.

Table 7. Stability Tests

\begin{tabular}{|c|c|c|}
\hline \multicolumn{3}{|c|}{ Hansen Test } \\
\hline Test & Statistic & P-Value \\
\hline \hline Joint Stability & 1.97 & 0.00 \\
\hline Variance & .41 & 0.07 \\
\hline Constant & .43 & 0.06 \\
\hline Real GDP & .41 & 0.07 \\
\hline Population & .42 & 0.06 \\
\hline Structural Break 1982 & 107.15 & 0.00 \\
\hline Structural Break 1991 & 11.02 & 0.00002 \\
\hline Structural Break 1995 & 1.22 & 0.34 \\
\hline
\end{tabular}

These results are not intended to definitively answer the question of the relationship between economic growth and environmental quality. They are quite suggestive, but represent only one more piece to a complicated puzzle that includes evidence on both sides of the issue. Because of the difficulty in measuring ecological concepts like biodiversity, methodological differences and data limitations, as well as the complicated nature of the underlying relationships between economic activity and a variety of measures of environmental quality, it is both inevitable and important that the debate continue.

\section{REFERENCES}

[1] Porter ME, van der Linde C. Toward a new conception of the environmental-competitiveness relationship. J Econ Perspect 1995; 9: 97-118.

[2] Freeman AM. The measurement of environmental and resource values; resources for the future. USA: Washington, DC 1993.

[3] López R. Environment as a factor of production: the effects of economic growth and trade liberalization. J Environ Econ Manage 1994; 27: 163-84.

[4] Selden TM, Song D. Environmental quality and development: is there a kuznets curve for air pollution emissions? J Environ Econ Manage 1994; 27: 147-62.

[5] Brock W, Taylor S. The green solow model. NBER working paper no. $10557,2004$.

[6] Dinda S. A theoretical basis for the environmental kuznets curve. Ecol Econ 2005; 53: 403-13.

[7] Grossman GM, Krueger AB. Environmental impacts of a north american free trade agreement. In: Garber PM, Ed. The MexicoU.S. Free Trade Agreement. Cambridge, MA: MIT Press 1994.

[8] Holtz-Eakin D, Selden TM. Stoking the fires? CO emissions and economic growth. J Public Econ 1995; 57: 85-101.

[9] Maddison D. Environmental kuznets curves: a spatial econometric approach. J Environ Econ Manage 2006; 51: 218-30.

[10] Paudel KP, Zapata H, Susanto D. An empirical test of environmental kuznets curve for water pollution. Environ Resour Econ 2005; 31: 325-48.

[11] Koop G, Tole L. Is there an environmental kuznets curve for deforestation? J Dev Econ 1999; 58: 213-44.

[12] Naidoo R, Adamowicz WL. Effects of economic prosperity on numbers of threatened species. Conserv Biol 2001; 15: 1021-29.

[13] Dietz S, Adger N. Economic growth, biodiversity loss and conservation effort. J Environ Manage 2003; 68: 23-35.

[14] Czech B, Krausman PR, Devers PK. Economic associations among causes of species endangerment in the United States. BioScience 2000; 50: 593-601.

[15] Reed K, Czech B. Causes of fish endangerment in the United States, or the structure of the American economy. Fisheries 2005; 30(7): $36-38$

[16] Brown GM, Shogren JF. Economics of the endangered species act. J Econ Perspect 1998; 12: 3-20. 
[17] Metrick A, Weitzman ML. Patterns of behavior in endangered species preservation. Land Econ 1996; 72: 1-16.

[18] Ando AW. Do interest groups compete? An application to endangered species. Public Choice 2003; 114: 137-59.

[19] Pearce DW, Moran D. The economic value of biodiversity. London: Earthscan 1994.

[20] Lawton JH, May R. Extinction Rate. Oxford England: Oxford University Press 1995.

[21] Jenkins M. Prospects for biodiversity. Science 2003; 302: 1175-77.

[22] Rosenzweig ML. Species diversity in space and time. NewYork: Cambridge University Press 1995.

[23] Vanreuse W, Van Dyck H. When functional habitat does not match vegetation types: a resource-based approach to map butterfly habitat. Biol Conserv 2007; 135(2): 202-11.
[24] Greenwald DN, Suckling KF, Taylor M. The Listing Record. In: Goble DD, Scott MJ, Eds. The endangered species act at thirty. Washington DC: Island Press 2006.

[25] Brown RL, Durbin J, Evans JM. Techniques for testing the constancy of regression relationships over time. J R Stat Soc 1975; Series B, 37: 149-92.

[26] Hansen B. Parameter instability in linear models. J Policy Model 1991; 14(4): 517-33.

[27] Stokstad E. Endangered Species act: appointee 'reshaped' science, says report. Science 2007; 316(5821): 37.

[28] Eilperin J. Bush appointee said to reject advice on endangered species. USA: Washington Post 2006.

[29] Kongsamut P, Tavares S, Rebelo D. Beyond balanced growth. Rev Econ Stud 2001; 68: 869-82.

(C) Chambers et al.; Licensee Bentham Open.

This is an open access article licensed under the terms of the Creative Commons Attribution Non-Commercial License (http://creativecommons.org/licenses/by$\mathrm{nc} / 3.0 /$ ) which permits unrestricted, non-commercial use, distribution and reproduction in any medium, provided the work is properly cited. 